\title{
Generalised Leukaemic Gingival Enlargement: a Case Report
}

\author{
Mechery Reenesh ${ }^{1}$, Singh Munishwar ${ }^{1}$, Saroj Kumar Rath ${ }^{2}$ \\ ${ }^{1}$ Division of Periodontology, Armed Forces Medical College, Pune, India. \\ ${ }^{2}$ Department of Dental Surgery, Armed Forces Medical College, Pune, India
}

\author{
Corresponding Author: \\ Reenesh Mechery \\ Department of Dental Surgery \\ Armed Forces Medical College \\ Pune-411040 \\ India \\ E-mail: captreenesh@gmail.com
}

\begin{abstract}
Background: Acute myeloblastic leukaemia is a malignant bone marrow neoplasm of myeloid precursors of white blood cells. Due to its high morbidity rate, early diagnosis and appropriate medical therapy is essential.

Methods: The article highlights normal blood alterations like anaemia, thrombocytopenia, leukocytosis and advanced diagnostic aids like flow cytometry, special staining as a diagnostic modality as well as for prognostic information in acute leukaemia, particularly as a tool for assigning lineage and facilitating further pathologic classification which may be helpful in influencing treatment strategies.

Results: On clinical examination the case presented with features of inflammatory gingival enlargement with presence of local deposits and calculus. Routine blood examination anaemia, thrombocytopenia, leukocytosis with haemoglobin 5.6 gm $\%$ and total leukocyte count of 1,12,000 / cu mm suggestive of leukaemia. Myeloperoxidase and leukocyte nonspecific esterase (NSE) special stain were used which showed presence of myeloblasts in the peripheral smear suggestive of acute myelocytic leukaemia. Flow cytometry were done which further helped in interpretation of these cells which showed to be strongly positive for CD45, CD13, CD14, and anti HLADR and moderately positive for CD4, CD34 and Anti MPO confirming to be case of AML-M4 with $57.73 \%$ gating.

Conclusions: Fact that gingival alterations are sometimes the first manifestations of the disease implies that dental professionals must be sufficiently familiarized with the clinical manifestations of systemic diseases. The timely referral by the general dentist for a suspicious lesion provided an early diagnosis and early intervention reducing the patient morbidity.
\end{abstract}

Keywords: acute myeloid leukemia; flow cytometry; gingival hyperplasia.

\author{
Accepted for publication: 25 September 2012. \\ To cite this article: \\ Reenesh M, Munishwar S, Rath SK. Generalised Leukaemic Gingival Enlargement: a Case Report. \\ J Oral Maxillofac Res 2012;3(3):e5 \\ URL: http://www.ejomr.org/JOMR/archives/2012/3/e5/v3n3e5ht.pdf \\ doi: $10.5037 /$ jomr.2012.3305
}




\section{INTRODUCTION}

Leukaemia is a hematologic disorder resulting from the proliferation of a clone of abnormal hematopoietic cells with impaired differentiation, regulation, and programmed cell death. Leukaemic cell multiplication at the expense of normal hematopoietic cells lines causes marrow failure, depressed blood cell count, and death as a result of infection, bleeding, or both [1]. The oral manifestations of leukaemia include gingival enlargement, oral ulcerations, gingival bleeding, petechia and mucosal pallor. Oral lesions occur in both acute and chronic form of all types of leukaemias; myeloid, lymphoid and monocytic. However, the oral manifestations are far more common in the acute stages of the disease and are most common in monocytic leukaemia [2].

Gingival enlargement because of infiltration of premature leukocytes in leukaemia is well documented in literature and is one of the most common symptoms leading to the diagnosis of leukaemia that directs the patients to seek dental consultation [3] . In this paper, we report a case of a patient who reported for bleeding gums to our department and was diagnosed with acute myeloid leukaemia incidentally on routine blood investigations followed by flow cytometry for staging of leukaemia.

\section{CASE DESCRIPTION AND RESULTS}

A 32 years old male patient reported to the Division of Periodontics, Armed Forces Medical College, Pune, India with the chief complaint of bleeding gum from last five months. He was apparently normal five months before and gradually developed pain and bleeding on brushing. On eliciting the medical history, patient was hospitalized six months before for breathlessness and enterocolitis. Patient also gave a history of mild weight loss and loss of appetite from last few months.

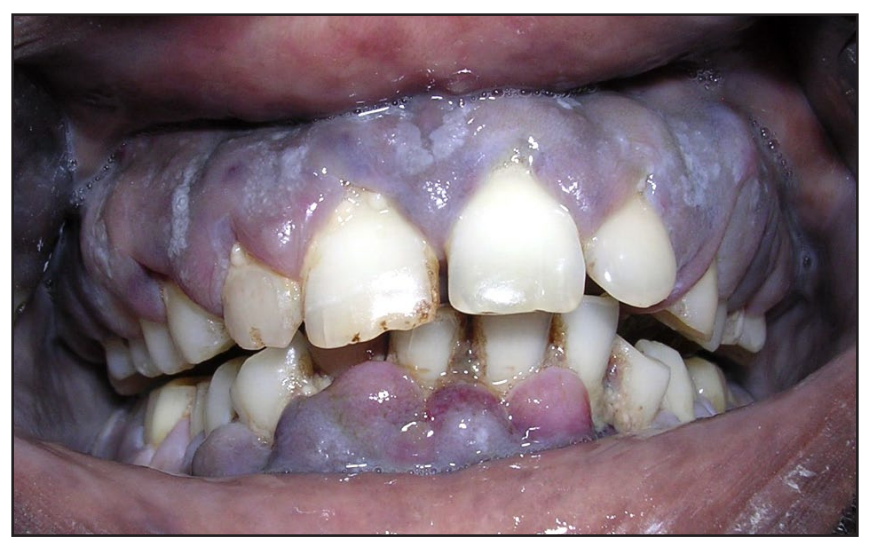

Figure 1. Generalized gingiva enlargement.
General physical examination revealed that he was moderately built, poorly nourished had signs of anaemia and skin looked pale but did not have signs of cyanosis and jaundice. On intraoral examination generalised gingival enlargement was noticed (Figure 1). Gingival was bluish in colour with presence of ecchymosis in the floor of the mouth (Figure 2). His oral hygiene was poor with presence of local factors. On palpation, gingiva was soft and oedematous without stippling and was tender on palpation. Based on systemic and intraoral examination patient was advised to undergo routine blood investigations in the Department of Pathology and was also advised to report back with all old blood and hospitalization reports. He was diagnosed with acute myeloid leukaemia (AMLM4) a day later by peripheral smear examination by special staining (Figures 3 and 4) and flow cytometry. His old reports of hospitalization were checked which revealed that he had hepatomegaly and fluid filled oedematous bowel loops suggestive of enterocolitis. His comparative blood profile and normal blood count is given in Table 1.

Flow cytometry was done with forward scattering (FSC) versus side scattering (SSC) in which $57.73 \%$ cells were gated and the cells included all atypical cells. Further interpretation of these cells revealed strongly positive for CD45, CD13, CD14, and anti HLADR and moderately positive for CD4, CD34 and Anti MPO (Figure 5). These cells were negative for CD10, CD79a, CD7 and CD20 giving an impression of AML-M4.

The patient was referred to haematooncologist for further management and chemotherapy but the patient expired four days later due to multi organ failure and secondary infection.

\section{DISCUSSION}

Leukaemia is classified as lymphocytic or myelocytic according to the lineage of white blood cells (WBC)

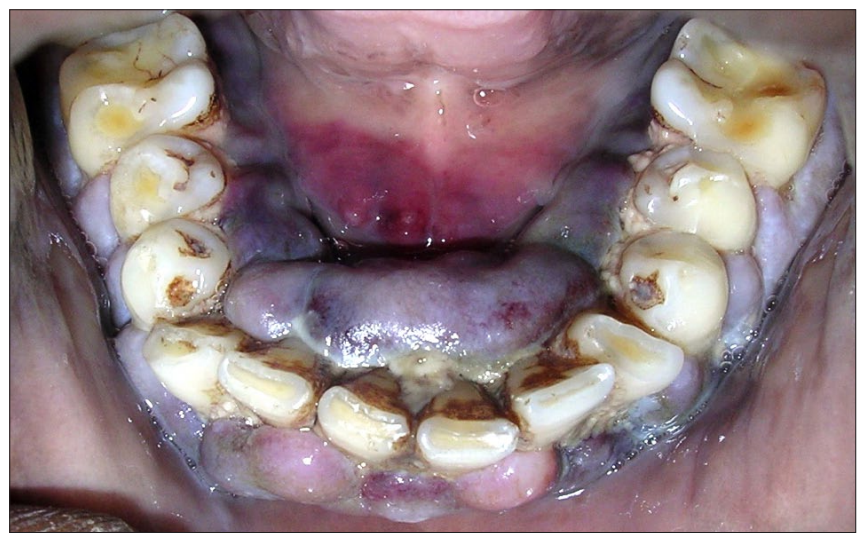

Figure 2. Bluish gingiva and echymosis in floor of the mouth. 


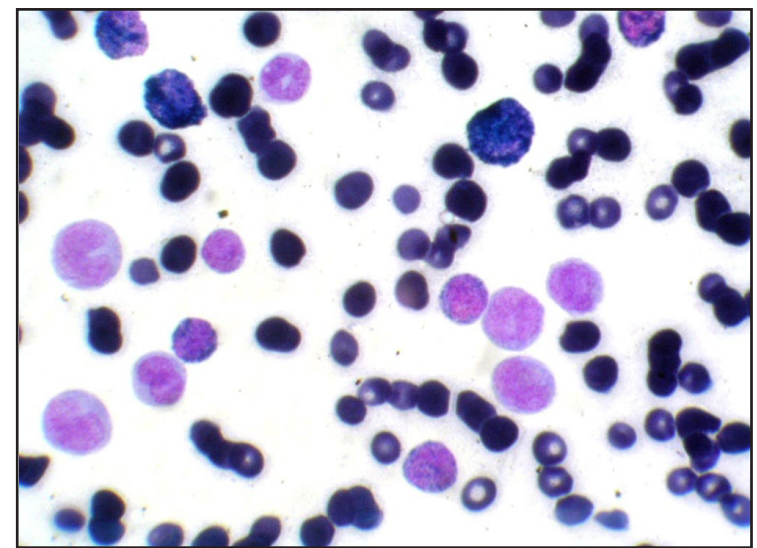

Figure 3. Peripheral smear MPO Positive (Myloperoxidase) myloid cells.

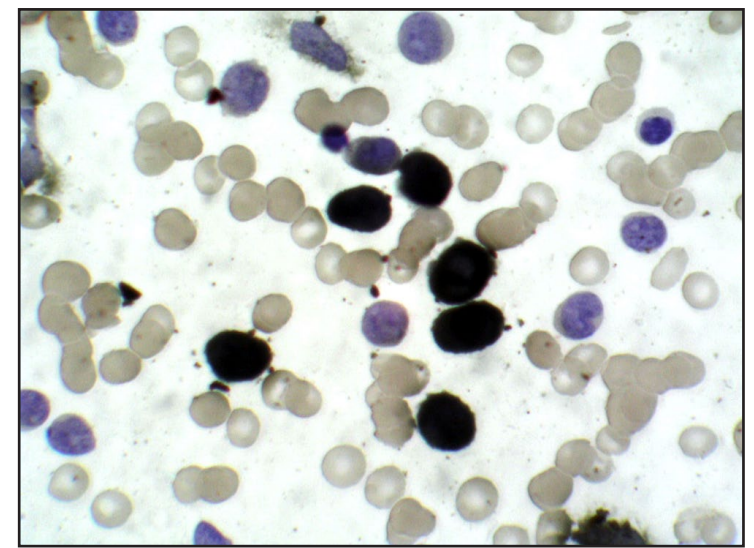

Figure 4. NSE Positive (Leukocyte nonspecific esterase) monocytoid cells.

Table 1. Comparison of blood indices

\begin{tabular}{|c|c|c|c|}
\hline & $\begin{array}{c}\text { Initial blood picture } \\
\text { (old hospitalization report) }\end{array}$ & $\begin{array}{l}\text { Present blood picture } \\
\text { (in department) }\end{array}$ & Normal value \\
\hline Haemoglobin & $6.9 \mathrm{gm} \%$ & $5.6 \mathrm{gm} \%$ & $11.5-16.5 \mathrm{gm} \%$ \\
\hline RBC & 3.17 million / cu mm & 1.41 million / cu mm & $3.5-6.0$ million / cu mm \\
\hline Platelets & $75,000 / \mathrm{cu} \mathrm{mm}$ & $25,000 / \mathrm{cu} \mathrm{mm}$ & $1,50,000-4,50,000 / \mathrm{cu} \mathrm{mm}$ \\
\hline TLC & $98,000 / \mathrm{cu} \mathrm{mm}$ & $1,12,000 / \mathrm{cu} \mathrm{mm}$ & $4,000-11,000 / \mathrm{cu} \mathrm{mm}$ \\
\hline DLC & $\begin{array}{c}\text { Neutrophils } 15 \% \\
\text { Eosinophil 4\% } \\
\text { Basophils } 0 \% \\
\text { Lymphocytes } 77 \% \\
\text { Myelocytes 4\% }\end{array}$ & $\begin{array}{c}\text { Neutrophils } 0.4 \% \\
\text { Lymphocytes } 10 \% \\
\text { Myeloblasts } 25 \% \\
\text { Monoblasts } 15 \% \\
\text { Promonocytes } 22 \% \\
\text { Monocytes } 20 \% \\
\text { Promyelocytes } 0.1 \% \\
\text { Myelocytes } 0.1 \% \\
\text { Metamyelo + band forms } 0.2 \% \text {. }\end{array}$ & $\begin{array}{c}\text { Neutrophils } 40-70 \% \\
\text { Eosinophil } 1-6 \% \\
\text { Basophils } 0 \text { - 1\% } \\
\text { Lymphocytes } 20-40 \% \\
\text { Monocytes } 2-10 \%\end{array}$ \\
\hline
\end{tabular}

$\mathrm{RBC}=$ Red blood corpuscles $; \mathrm{TLC}=$ Total leukocyte count; DLC $=$ Differential leukocyte count.

involved; a subgroup of the myelocytic leukaemias is monocytic leukaemia. According to their evolution, leukaemias can be acute, which is rapidly fatal; subacute; or chronic. In acute leukaemia, the primitive "blast" cells are released into the peripheral circulation, whereas in chronic leukaemia, the abnormal cells tend to be more mature with normal morphologic characteristics and function when released into the circulation [1].

The two most commonly used classification schemata for AML are World Health Organization (WHO) system and French-American-British (FAB) classification system. WHO classify AML into four subtypes as; AML with characteristic genetic abnormalities, AML with multilineage dysplasia, AML and myelodysplastic syndrome (MDS) or myeloproliferative diseases therapy related and AML not otherwise categorized [4].

FAB system commonly classify AML under 8 subgroups as M0 (undifferentiated leukaemia),
M1 (acute myeloblastic leukaemia), M2 (acute myeloblastic leukaemia with maturation), M3 (acute promyelocytic leukaemia), M4 (acute myelo-monocytic leukaemia), M5 (acute monocytic leukaemia), M6 (acute erythroblastic leukaemia), and M7 (acute megakaryoblastic leukaemia). The morphologic subtype of AML also include a rare type not included in FAB system as ninth subtype, M8, as acute basophilic leukaemia [5].

Patients with AML generally present with symptoms related to complications of pancytopenia (anaemia, neutropenia, and thrombocytopenia) including weakness, and easy fatigue, infections of variable severity, and/or hemorrhagic findings such as gingival bleeding, ecchymoses, epistaxis or menorrhagia. In some cases atypical features like chin numbness and tooth pain has also been reported [6]. The expression of these signs is more common in acute and sub-acute 


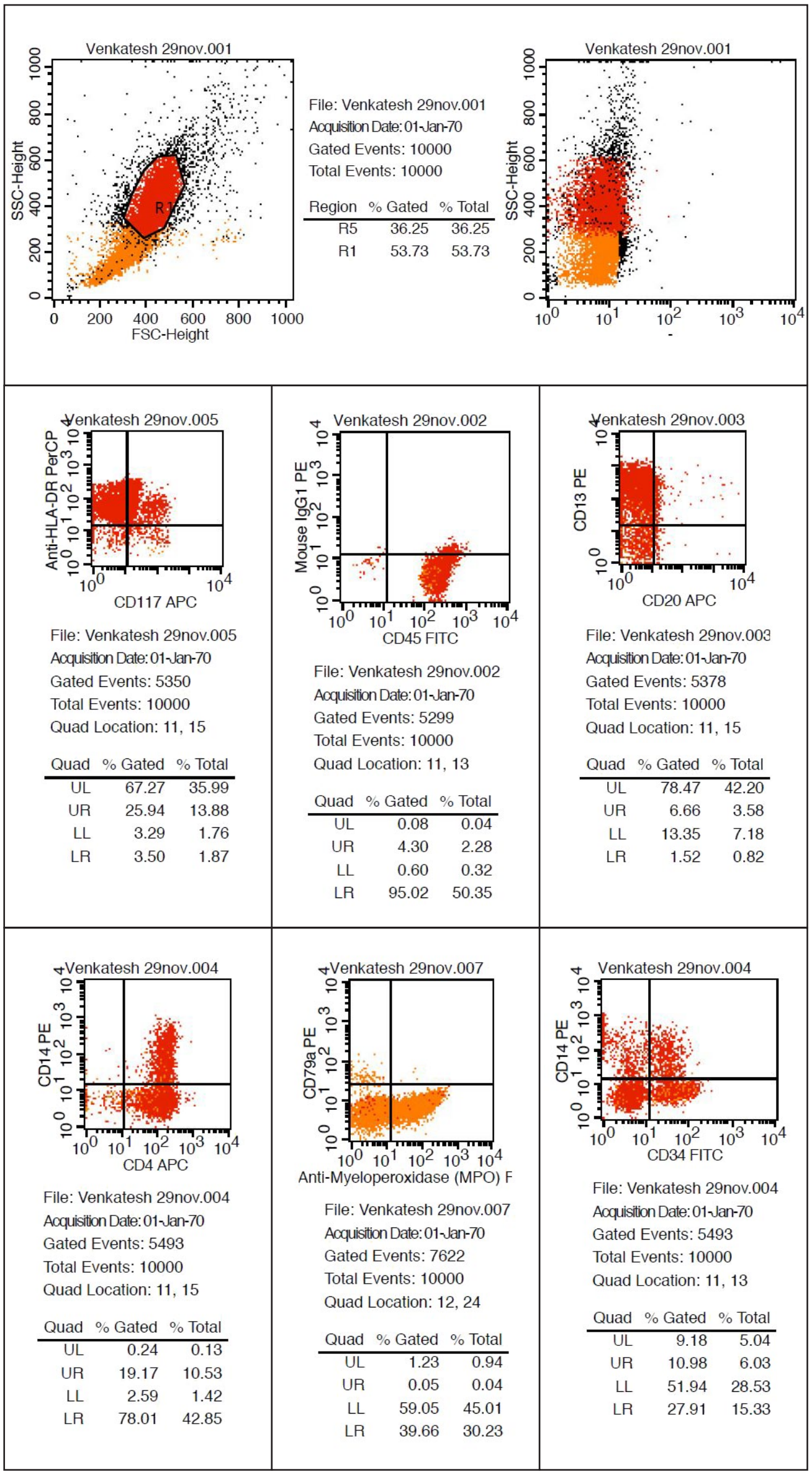

Figure 5. Flow cytometry (Positive for CD34, CD45, CD13, CD33, CD14, CD4, Anti-HLA DR, CD11 and anti MPO). 
forms of leukaemia than in chronic forms. Oral manifestations in patient with leukaemia have been described in all subtypes of AML, chronic myeloid leukaemia (CML), acute lymphocytic leukaemia (ALL), and chronic lymphocytic leukaemia (CLL). Gingival infiltration represents a $5 \%$ frequency as the initial presenting complication of AML. Gingival infiltration of leukemic cells is most commonly seen in acute monocytic leukaemia (M5) and acute myelomonocytic leukaemia (M4). The proposed hypothesis for gingival involvement is considered due to its microanatomy and expression of endothelial adhesion molecules which enhances infiltration of leukocytes [7]. Dreizen et al. [] in an observational study have reported gingival involvement in $66.7 \%$ of 1076 cases of AML M5 cases and $18.5 \%$ in M4.

Leukaemia cell gingival infiltrate is not observed in edentulous individuals, suggesting that local irritation and trauma associated with the presence of teeth may play a role in the pathogenesis of this abnormality $[\underline{6}, \underline{7}]$. The case described here had adequate local factors which are the predisposing factor for gingival enlargement.

The specific type of leukaemia must be investigated in order to provide the best treatment and most accurate prognosis. Special leukaemia stains help to distinguish one cell type from another. Commonly used special staining methods are sudan black, periodic acid-schiff, terminal deoxynucleotidyl transferase stain, leukocyte alkaline phosphatise, tartrate-resistant acid phosphatase stain, myeloperoxidase (MPO), leukocyte specific and nonspecific esterase $[\underline{9}, \underline{10}]$. In our case myeloperoxidase and leukocyte nonspecific esterase (NSE) special stain were used which showed presence of myeloblasts in the peripheral smear suggestive of acute myelocytic leukaemia.

Flow cytometry works on the principle that when a LASER beam is passed through a particle like a cell in a hydrodynamically focused stream, the light will cause scattering and this fluorescent light is picked by an electronic detector which analyze and determines the physical and chemical nature of the particle or cell. The data so generated by flow cytometry are plotted in single or two dimension dot plots depending on the fluorescence intensity. The plot can be sequentially separated creating a series of subset extractions called "Gates" [10]. In our case we have used flow cytometry for the determination of diagnosis, prognosis and progression of the disease. The report of flow cytometry has confirmed the present case to be a case of AML M4 as the cells were strongly positive for CD 45, CD13, CD14 and anti HLADR.
The treatment of AML still remains a highly specialised one associated with high mortality and morbidity [11]. The management modalities include aggressive multidrug chemotherapy and allogenic bone marrow transplantation. Periodontal and dental treatment for patients with leukaemia should always be planned after medical evaluation and physicians consent. If systemic condition allows periodontal debridement (scaling and root planing) should be performed under antibiotic coverage. Twice daily rinsing with $0.12 \%$ chlorhexidine gluconate is recommended after oral hygiene procedures but, periodontal surgeries should be avoided until remission []]

\section{CONCLUSIONS}

The mechanisms underlying AML and the reasons for difficulties of treating patients with acute myeloblastic leukaemia have only partly been unravelled. This case reminds that dentist and physicians should be aware of the importance of recognizing oral manifestations of systemic diseases as oral cavity is considered to be the mirror of systemic health. A patient seeking dental treatment for bleeding gums was incidentally diagnosed as leukaemia based on thorough dental and medical history followed by definitive diagnosis by peripheral staining and flow cytometry as presented in this case. Therefore, the dentist may be the first person to diagnose such cases. The timely referral by the general dentist for a suspicious lesion provided an early diagnosis and early intervention reducing the patient morbidity. Therefore the role of dental practitioner in diagnosing a case of leukaemia for better management and prognosis cannot be overemphasized.

\section{ACKNOWLEDGMENTS AND DISCLOSURE STATEMENTS}

We would like to thank Col. Jyothi Kotwal, Professor, Lt. Col. Ajay Malik, Associate Professor and Dr. Sandeep Kumar Dahiya Department of Pathology, Armed Forces Medical College, Pune for their support and assistance during the clinical phases of diagnosis. There are no conflicts of interest related to this study. 


\section{REFERENCES}

1. Cooper CL, Loewen R, Shore T. Gingival hyperplasia complicating acute myelomonocytic leukemia. J Can Dent Assoc. 2000 Feb;66(2):78-9. Review. [Medline: 10730004] [FREE Full Text]

2. Eversole LR. Benign tumors of the oral cavity. In: Greenberg MS, Glick M, editors. Burket's Oral medicine: Diagnosis and treatment. 10th edition. Ontario: BC Decker Inc.; 2003. p. 137-94.

URL: http://web.squ.edu.om/med-Lib/MED_CD/E CDs/oral\%20medicine/startme.pdf

3. Carranza FA, Hogan EL. Gingival enlargement. In: Newman MG, Takei HH, Carranza FA. Clinical periodontology. 10th edition. Philadelphia: WB Saunders Co; 2002. p. 279-96.

4. Henderson ES: Definition and classification, in Henderson ES, Lister TA: Leukemia, 5th edition Philodelphia, WB Saunders Co; 1990. p. 13-5.

5. Bennett JM, Catovsky D, Daniel MT, Flandrin G, Galton DA, Gralnick HR, Sultan C. Criteria for the diagnosis of acute leukemia of megakaryocyte lineage (M7). A report of the French-American-British Cooperative Group. Ann Intern Med. 1985 Sep;103(3):460-2. [Medline: 2411180]

6. Dean AK, Ferguson JW, Marvan ES. Acute leukaemia presenting as oral ulceration to a dental emergency service. Aust Dent J. 2003 Sep;48(3):195-7. [Medline: 14640374] [doi: 10.1111/j.1834-7819.2003.tb00032.x]

7. Wu J, Fantasia JE, Kaplan R. Oral manifestations of acute myelomonocytic leukemia: a case report and review of the classification of leukemias. J Periodontol. 2002 Jun;73(6):664-8. [Medline: 12083541] [doi: 10.1902/jop.2002.73.6.664]

8. Dreizen S, McCredie KB, Keating MJ, Luna MA. Malignant gingival and skin “infiltrates" in adult leukemia. Oral Surg Oral Med Oral Pathol 1983 Jun; 55(6):572-9. [doi: 10.1016/0030-4220(83)90373-0]

9. Anil S, Smaranayake LP, Nair RG, Beena VT. Gingival enlargement as a diagnostic indicator in leukaemia. Case report. Aust Dent J. 1996 Aug;41(4):235-7. [Medline: 8870276] [doi: 10.1111/j.1834-7819.1996.tb04865.x]

10. Parisi E, Draznin J, Stoopler E, Schuster SJ, Porter D, Sollecito TP. Acute myelogenous leukemia: advances and limitations of treatment. Oral Surg Oral Med Oral Pathol Oral Radiol Endod. 2002 Mar;93(3):257-63. Review. [Medline: 11925533] [doi: 10.1067/moe.2002.121988]

11. Fauci A.S, Braunwald E, Kasper D.L, Hauser S.L, Longo D.L, Jameson J.L, Lascalzo J. Harrison's Principles of Internal Medicine. 7th edition. McGraw-Hill Access Medicine; 2008. p. 271-83.

\section{To cite this article:}

Reenesh M, Munishwar S, Rath SK. Generalised Leukaemic Gingival Enlargement: a Case Report.

J Oral Maxillofac Res 2012;3(3):e5

URL: http://www.ejomr.org/JOMR/archives/2012/3/e5/v3n3e5ht.pdf

doi: $10.5037 /$ jomr.2012.3305

Copyright (C) Reenesh M, Munishwar S, Rath SK. Accepted for publication in the JOURNAL OF ORAL \& MAXILLOFACIAL RESEARCH (http://www.ejomr.org), 25 September 2012.

This is an open-access article, first published in the JOURNAL OF ORAL \& MAXILLOFACIAL RESEARCH, distributed under the terms of the Creative Commons Attribution-Noncommercial-No Derivative Works 3.0 Unported License, which permits unrestricted non-commercial use, distribution, and reproduction in any medium, provided the original work and is properly cited. The copyright, license information and link to the original publication on (http://www.ejomr.org) must be included. 